\title{
Two kinds of anti-ricin antibody and ricin interaction evaluated by biosensor based on imaging ellipsometry
}

\author{
Yu Niu ${ }^{\text {a,b }}$, Jie Zhuang ${ }^{c}$, Li Liu ${ }^{\text {a }}$, Xiyun Yan ${ }^{\text {c }}$, Gang Jin ${ }^{\mathrm{a}, *}$ \\ a NML, Institution of Mechanics, Chinese Academy of Sciences, \#15, Bei-si-huan West Road, Beijing 100190, China \\ ${ }^{\mathrm{b}}$ Graduate University of the Chinese Academy of Sciences, \#19, Yu-quan Road, Beijing 100049, China \\ ${ }^{\mathrm{c}}$ Institution of Biophysics, Chinese Academy of Sciences, \#15, Da-tun Road, Beijing 100101, China
}

\section{A R T I C L E I N F O}

Available online 21 December 2010

Keywords:

Ricin detection

Antigen-antibody interaction

Biosensor

Imaging ellipsometry

\begin{abstract}
A B S T R A C T
In order to meet the requirements of antibody comparison and evaluation, the optimization for the surface modification, ligand immobilization, unspecific blocking and ligand-receptor interaction condition is introduced to the biosensor based on imaging ellipsometry (BIE), so that it may serve as an antibody screening platform to evaluate antibody-antigen interactions. Two kinds of anti-ricin antibody named pVHHS1 and 5S1R are immobilized in a patterned array format on the silicon surface modified with succinic anhydride, respectively, to form a sensing surface. Ricin and its similar toxin abrin as the reference in solution are delivered, respectively, on the patterned sensing surface for anti-ricin antibody and ricin interaction. The limit of detection value of ricin detected by pVHHS1 and 5S1R is obtained as $1 \mu \mathrm{g} / \mathrm{ml}$ and $5 \mathrm{ng} / \mathrm{ml}$, respectively. Results show that pVHHS1 and 5S1R specifically bind with ricin but not with abrin, which is in accordance with ELISA's result.
\end{abstract}

(c) 2010 Elsevier B.V. All rights reserved.

\section{Introduction}

With the improvement of monoclonal antibody technique $[1,2]$ and genetic engineering technique [3], antibody application has achieved good performance in various fields [4] and some conventional methods have been focused on antibody screening [5-7]; meanwhile several novel techniques have enormously mushroomed for characterizing antibody in diagnostic and therapeutic applications [8-10].

The concept of biosensor based on imaging ellipsometry (BIE) [11,12] which combined high spatial resolution imaging ellipsometry with protein microarray was proposed in 1995. Although it has been successfully used in several biological and clinical detection applications including tumor markers [13], five markers of Hepatitis B Virus [14], Phage M13KO7 [15], and Avian Influenza Virus [16], it is possible to improve its functions to meet the increasing requirements of biomedical applications [17]. The sensitivity and flexibility of the BIE are very important for practical applications. The sensitivity is dependent not only upon the resolution of imaging ellipsometry but also upon the bio-system of ligand-receptor on the microarray that is the bioactivity and its act is related to the ligand screening to choose the best among the ligands upon their bioactivity, ligand immobilization, unspecific blocking, interaction conditions, etc. [17]. Two kinds of anti-ricin antibody named pVHHS1 and 5S1R are evaluated with

\footnotetext{
* Corresponding author. Tel./fax: +86 1082544138 .

E-mail address: gajin@imech.ac.cn (G. Jin).
}

BIE as an antibody screening platform to show sensitivity and flexibility.

Ricin found in castor beans [18] is considered to be one of the most potent plant toxins [19] which has an estimated oral lethal dose less than $20 \mathrm{mg} / \mathrm{kg}$ body weight in human [20]. Therefore, anti-ricin antibody can identify and neutralize ricin fast and efficiently and is of great significance for diagnosis and treatment to those exposed to ricin poison [21-23]. We need to obtain their limit of detection (LOD) value, and compare with ELISA for a confirmation.

\section{Materials and methods}

\subsection{Chemicals and substrates}

Silicon wafers are purchased from Beijing GRINM semiconductor Materials Company. 1-(3-Dimethylaminopropyl)-3-ethylcarbodiimide hydrochloride (EDC), succinic anhydride and aminopropyltriethoxysilane (APTES) are purchased from Acros Organics. N-Hydroxy-succinimide (NHS), blocking buffer, PBST buffer (PBS containing 0.05\% Tween20 ) and immunoglobulin $G(\operatorname{IgG})$ from goat serum are purchased from Sigma-Aldrich.

\subsection{Ricin and its antibody}

Ricin, abrin [19] and two kinds of anti-ricin antibody named pVHHS1 and 5S1R are kindly provided by Professor Yan's Group in the Institute of Biophysics, the Chinese Academy of Sciences. Ricin and abrin are stored in PBST solution, and their concentrations are $0.2 \mathrm{mg} /$ 
$\mathrm{ml}$ and $0.1 \mathrm{mg} / \mathrm{ml}$, respectively. pVHHS1 is an anti-ricin single domain pentamer antibody derived from VHHS1 which is subcloned into pET30a $(+)$ vector and fused to the $C$ terminal of verotoxin B. 5S1R is an anti-ricin single domain pentamer antibody self-assembled by $\mathrm{S} 1 \mathrm{R}$ which is subcloned into $\mathrm{pED} 2$ vector and fused to the $\mathrm{N}$ terminal of verotoxin $\mathrm{B}$.

\subsection{BIE}

To carry out high throughput immunoassays of molecular interaction, BIE has been improved in our laboratory during the last decade [17,24-26]. Now, it is mainly composed of a micro-fluidic reactor array system and an imaging ellipsometry reader.

A micro-fluidic reactor array system that integrated 48 independent flow channels serving as the microarray reactor $[26,27]$ is used for a series of continuous processes, including surface patterning, solution delivery, ligand immobilization, blocking, target capture, rinsing, etc. The micro-fluidic array system is composed of four main parts: sample reservoir, multi-cell array, multi-channels and pumps. When a silicon wafer substrate is placed on the multi-cell array to form closed paths, a patterned microarray can be fabricated because each cell has an independent inlet and outlet for solution delivery. The inlet micro-channels are connected to the sample reservoir and the outlet micro-channels are connected with pumps offering negative pressure. Using the micro-fluidic reactor system, various ligands are delivered to different cells to form a sensing array, and each sensing surface can be prepared homogeneously.

Imaging ellipsometry acts as the data acquisition of the microarray. Imaging ellipsometry is an enhancement of standard single-beam ellipsometry, which combines the power of ellipsometry with microscopy and works in the off-null mode $[11,12,28]$. Upon the high sensitivity requirement for weak affinity biomolecular interactions, its sensitivity has been improved by the polarization setting optimization, the wavelength optimization and an imaging device with low noise [17]. It can be utilized for the visualization of ultra-thin films and slight surface concentration change [11,12]. Here, it is used to quantify the thickness distribution of protein layers [26,28]. A slight variation of thickness can be remarkably distinguished by imaging ellipsometry and the result is represented by images in grayscale format ( 8 bits, 0 255 grayscale or 10 bits, 1024 grayscale) [26]. The grayscale value is approximately linearly proportional to the thickness corresponding to the surface concentration [28].

\subsection{BIE operation}

The general detection procedure using BIE can be separated into the following successive steps. First, the microarray is modified with chemical reagents to form a chemically modified surface. Then, the modified microarray is placed in the micro-fluidic reactor system to form patterned cells in an array format. Ligand solutions are pumped into each cell to immobilize ligand on the microarray in order to form a sensing surface. After that, the analyte solution is delivered to react with the ligands. Finally, the microarray is sampled by the imaging ellipsometry reader to determine molecular interaction results.

In order to improve BIE performance, some optimization in the experimental conditions including surface modification, ligand immobilization, unspecific blocking and interaction condition is needed during the detection process. Surface modification plays a crucial role not only in the presentation of ligand on the sensing surface but also in the prevention of unspecific binding [26]. The surface modification approach with APTES and succinic anhydride is chosen for ricin detection by comparing several common modification methods described in previous reports [26,29-31]. Ligand surface concentration is intimately associated with the amount of complex and is regarded as a remarkable factor that influenced detection sensitivity and range [17]. Its optimized value should be lower than the saturation adsorption concentration; meanwhile, it is determined by the maximum of ligand-receptor complex. For the optimized ligand surface concentration among different concentrations ranging from $100 \mathrm{ng} / \mathrm{ml}$ to $100 \mu \mathrm{g} / \mathrm{ml}$ and the flux of $1 \mu \mathrm{l} / \mathrm{min}$ during $15 \mathrm{~min}$ for the ligand immobilization, the concentration of pVHHS1 and 5S1R at $25 \mu \mathrm{g} / \mathrm{ml}$ is used for ricin detection. In addition, some other experimental conditions such as flow rate, solution volume, blocking reagent and rinsing buffer are optimized in advance and their results are demonstrated in the following details.

\subsubsection{Silicon wafer preparation and surface modification}

Silicon wafer is used as solid surface for imaging ellipsometry biosensor. Due to the throughput of 48 independent channels, the silicon slides are cut into $25 \times 13 \mathrm{~mm}^{2}$ rectangular pieces. In order to wash out the organic and inorganic pollution, silicon wafers are cleaned with a mixture solution of $30 \% \mathrm{H}_{2} \mathrm{O}_{2}$ and concentrated $\mathrm{H}_{2} \mathrm{SO}_{4}$ $(1: 3 \mathrm{v} / \mathrm{v})$ for $30 \mathrm{~min}$. After being thoroughly rinsed with deionized water and pure ethanol, these silicon wafers are treated with an ethanol solution of APTES (5\% APTES and 95\% pure ethanol) and incubated for about $2 \mathrm{~h}$ at room temperature [30]. Following intensive rinsing in pure ethanol, the silicon wafers silanized with APTES are reacted with over-saturated succinic anhydride in ethanol overnight. After being rinsed with pure ethanol, the silicon wafers are stored in pure ethanol for ligands immobilization [16].

\subsubsection{Detection of ricin}

When a modified silicon wafer is placed into the micro-fluidic reactor system, $10 \mu \mathrm{l}$ of a mixture solution which is prepared with NHS and EDC at the concentration of $0.05 \mathrm{~mol} / \mathrm{ml}$ and $0.05 \mathrm{~mol} / \mathrm{ml}$ in deionized water is added to the micro-fluidic reactor system and passed through the surface at a flow rate of $5 \mu \mathrm{l} / \mathrm{min}$. With NHS and EDC, carboxyl groups on the substrate could react with the amino groups of the protein. Then, $15 \mu \mathrm{l}$ per unit of pVHHS1 and 5S1R as ligands diluted in PBST buffer at the concentration of $25 \mu \mathrm{g} / \mathrm{ml}$ is immobilized at a flow rate of $1 \mu \mathrm{l} / \mathrm{min}$ on the substrate for $15 \mathrm{~min}$. After being rinsed with PBST ( $50 \mu \mathrm{l} / \mathrm{unit}$ at $15 \mu \mathrm{l} / \mathrm{min}$ ) and blocked by blocking buffer $(30 \mu \mathrm{l} / \mathrm{unit}$ at $1 \mu \mathrm{l} / \mathrm{min})$, a multiplex microarray containing anti-ricin antibody sensing surface array is formed. Subsequently, $50 \mu \mathrm{g} / \mathrm{ml}$ ricin diluted in PBST is delivered to the microfluidic system at a flow rate of $1 \mu \mathrm{l} / \mathrm{ml}(20 \mu \mathrm{l} / \mathrm{unit})$. Abrin as similar to ricin but does not interact with anti-ricin antibody is set as the negative control. After being rinsed with plenty of PBST and dried under nitrogen, the microarray is sampled and recorded as images in grayscale by the imaging ellipsometry reader.

\subsubsection{LOD value of ricin detected by pVHHS1 and $5 S 1 R$}

The LOD value is the lowest detection quantity of an analyte that can be distinguished from the absence of the analyte within a stated confidence limit [32], and it is formally defined as the concentration of analyte required to give a signal equal to the average of the analyte plus three times the standard deviation of the blank control [32,33]. Thus, determining the LOD value of ricin by the anti-ricin antibody, is to detect the lowest detection concentration of ricin while there is an increase caused by anti-ricin antibody and ricin complex over 3 times of standard deviation of the blank control.

pVHHS1 and 5S1R as ligands are immobilized to form the sensing surface as mentioned previously. Meanwhile, IgG isolated from goat serum as the blank control is assembled on the substrate under the same condition. After being thoroughly rinsed with PBST and blocked by blocking buffer, ricin solutions at a series of concentration ranging from $0.5 \mathrm{ng} / \mathrm{ml}$ to $5 \mu \mathrm{g} / \mathrm{ml}$ are separately added to the micro-fluidic system at a flow rate of $1 \mu \mathrm{l} / \mathrm{ml}$ and a volume of $20 \mu \mathrm{l} / \mathrm{unit}$. After being thoroughly rinsed and dried by nitrogen blow, the microarray is sampled by an imaging ellipsometry reader. 


\subsection{ELISA operation}

Microtitre plates are coated with $5 \mu \mathrm{g} / \mathrm{ml}$ purified ricin in $0.05 \mathrm{~mol} /$ $1 \mathrm{NaHCO}_{3}$ (pH 9.6) at $4{ }^{\circ} \mathrm{C}$ overnight, and are washed three times with PBST. Unbound sites are blocked with $3 \%(\mathrm{w} / \mathrm{v})$ bovine serum albumin at $37^{\circ} \mathrm{C}$ for $1 \mathrm{~h}$. pVHHS1 and 5S1R at different concentrations and anti-c-Myc antibody are added at $37^{\circ} \mathrm{C}$ for $1 \mathrm{~h}$ before and after being rinsed with PBST. Then, horseradish peroxidase (HRP)-labeled goat anti-mouse $\operatorname{IgG}$ is added at $37^{\circ} \mathrm{C}$ for $45 \mathrm{~min}$ and microtitre plates are washed three times with PBST. Finally, 3,3',5,5'-tetramethylbenzidine substrate solution is added to the plates to interact with HRP for $5 \mathrm{~min}$, which results in color change. After stopping the color reaction by $2 \mathrm{~mol} / \mathrm{H} \mathrm{H}_{2} \mathrm{SO}_{4}$, the absorbance of each well is measured at $450 \mathrm{~nm}$ with a Bio-Rad ELISA reader.

\section{Results}

\subsection{Detection of ricin by BIE}

To detect ricin, abrin as similar to ricin is prepared under the same condition and set as the negative control. Results are shown in image in Fig. 1 and the corresponding numerical values are listed in Table 1. pVHHS1 and 5S1R are immobilized in columns a and b units of the microarray, and then they are reacted with ricin and abrin in rows 2 and 3 units, respectively. Row 1 is the ligand control. Compared with the ligand control, the grayscale value of units in the microarray where pVHHS1 and 5S1R antibody reacted with ricin increases

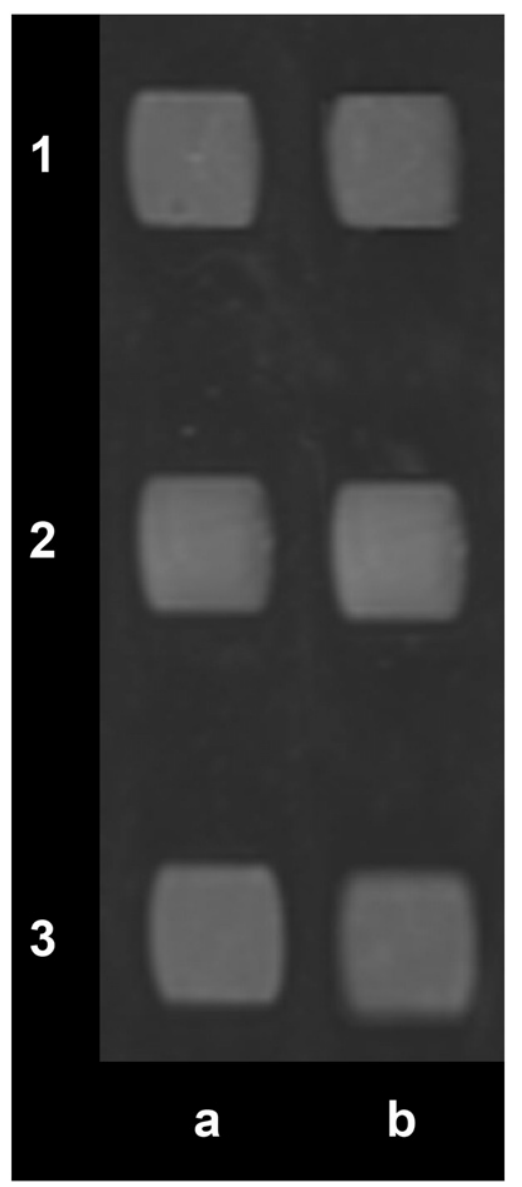

Fig. 1. Image in grayscale for ricin detection by BIE. pVHHS1 and 5S1R are immobilized in columns a and b, respectively. The microarray is blocked by blocking buffer after ligand immobilization, while ricin and abrin are added in rows 2 and 3, respectively. Thus, rows 1 and 3 are the ligand control and the negative control to the two kinds of anti-ricin antibody, respectively.
Table 1

Grayscale values of sensing units in the microarray corresponding to Fig. 1.

\begin{tabular}{llr}
\hline & pVHHS1 & 5S1R \\
\hline Ligand & 101.2 & 98.0 \\
Ricin & 108.9 & 114.1 \\
Abrin & 102.0 & 99.1 \\
\hline
\end{tabular}

remarkably, while those reacted with abrin still keep nearly constant. It indicates that pVHHS1 and 5S1R can recognize and interact with ricin but not with abrin. Moreover, compared with the negative control, the differential values in the grayscale are 6.9 and 15.0 in pVHHS1 and 5S1R sensing units, respectively, which suggest that the binding affinity of 5S1R with ricin is much higher than that of pVHHS1.

\subsection{LOD value of ricin detected by pVHHS1 and $5 S 1 R$}

In order to measure the LOD value of ricin by two kinds of antiricin antibody, IgG isolated from goat serum in PBST buffer at the concentration of $25 \mu \mathrm{g} / \mathrm{ml}$ is immobilized in a microarray to perform the blank control. Calculating 20 replicates, standard deviation of the blank control is 1.4 in grayscale shown in Fig. 2.

Results of nine concentrations of ricin detection in duplicate are demonstrated in Fig. 3. The average grayscale value of pVHHS1, 5S1R ligand and standard deviation of the blank control are 101.2, 98.0 and 1.4 , respectively. Thus, the grayscale value corresponding to the LOD value of ricin detected by anti-ricin antibody pVHHS1 and 5S1R should be greater than 105.4 , and 102.2 , so that the deduced LOD values of ricin by pVHHS1 and $5 \mathrm{~S} 1 \mathrm{R}$ are $1 \mu \mathrm{g} / \mathrm{ml}$ and $5 \mathrm{ng} / \mathrm{ml}$, respectively.

\subsection{Discussion on specificity, sensitivity and reproducibility of BIE}

Due to the label-free characteristic of BIE and several processes to avoid non-specific adsorption, BIE presents high specificity in previous report [14]. In the ricin detection, the specificity in BIE is estimated by introducing abrin which is similar to ricin with the same molecular weight to be the negative control. Compared with the ligand control, only a slight signal increase is observed in the presence of abrin in pVHHS1 and 5S1R sensing units about 0.8 and 1.2, which is less than the standard deviation of 1.4 calculated by 20 replicates of IgG as the blank control. It suggests that non-specific signal does not influence the specific detection and the specificity is still good enough for ricin detection.

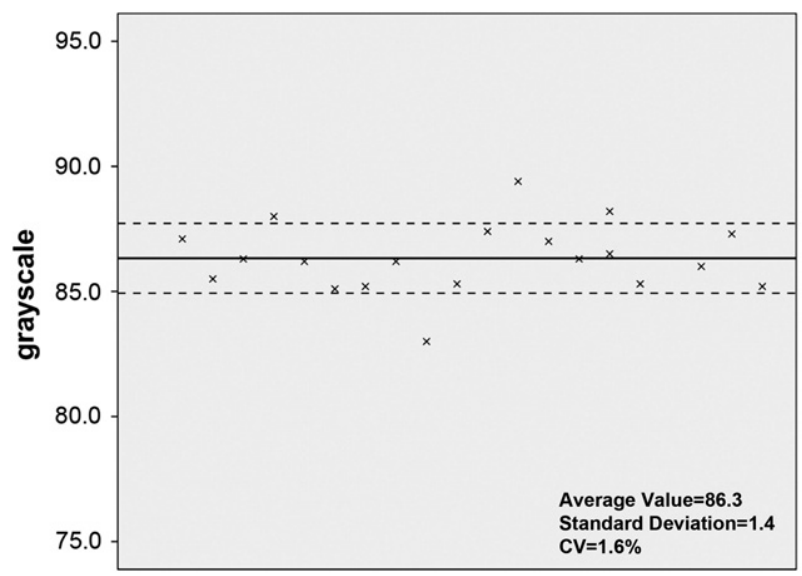

Number of the Blank Control

Fig. 2. Results of 20 replicates of the blank control. The solid line represents their average, while the dotted line shows the standard deviation. The coefficient of variation (CV) is $1.6 \%$, which indicates good reproducibility. 


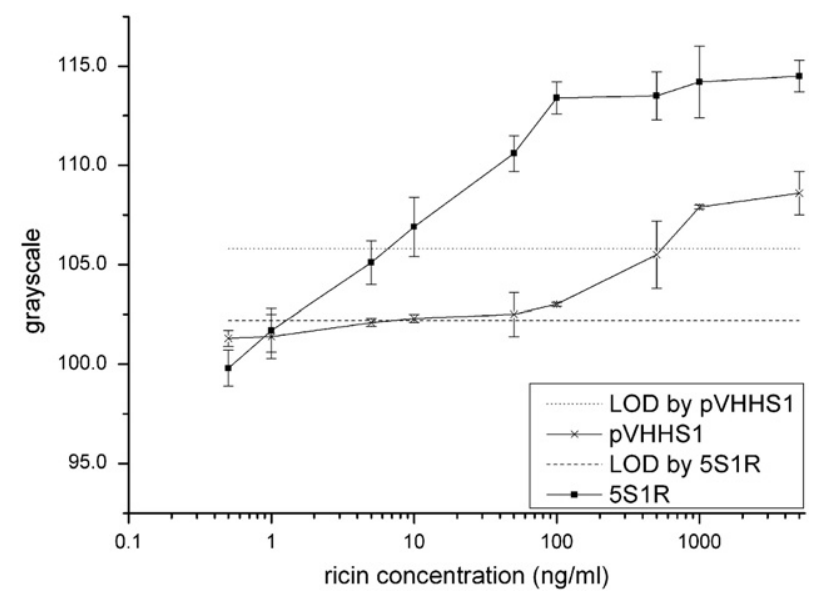

Fig. 3. Detection results for nine concentrations of ricin detected by pVHHS1 and 5S1R in duplicate.

The sensitivity in BIE for ricin detection is evaluated by monitoring the variance of BIE signal in the grayscale value on a series of ricin concentration. For 5S1R ligand sensing units, BIE signal increases with the ricin concentration increase ranging from $0.5 \mathrm{ng} / \mathrm{ml}$ to $100 \mathrm{ng} / \mathrm{ml}$. It reveals that the detection sensitivity is in the order of $\mathrm{ng} / \mathrm{ml}$ much lower than the oral lethal dose of ricin.

The reproducibility in BIE is assessed both in the same microarray and among duplicates of independent assay. The coefficient of variation (CV) among 20 replicates of IgG immobilized in the same microarray as the blank controls is $1.6 \%$. CV between two independent assays is calculated by the duplicate in measuring the LOD value and the $\mathrm{CV}$ is less than $2.0 \%$. It is demonstrated that BIE has an overwhelming reproducibility, which may meet the standard of clinical diagnosis.

\subsection{Confirmation by ELISA}

ELISA as a common method to detect the biomolecular interaction is used to test the binding ability between ricin and anti-ricin pVHHS1 and 5S1R. The results show that pVHHS1 does not detect ricin until its concentration reaches to $62.5 \mu \mathrm{g} / \mathrm{ml}$, while $5 \mathrm{~S} 1 \mathrm{R}$ can be recognized by ricin once its concentration is greater than $250 \mathrm{ng} / \mathrm{ml}$, which indicates that the binding ability of 5S1R with ricin may be 250 times higher than that of pVHHS1. Compared with LOD value measured by BIE, the result obtained by ELISA is in accordance with BIE.

\section{Conclusions}

BIE has been successfully used for antibody evaluation in the application of two kinds of anti-ricin antibody interaction with ricin. pVHHS1 and 5S1R are proved to react with ricin rather than abrin. Their LOD values are $1 \mu \mathrm{g} / \mathrm{ml}$ and $5 \mathrm{ng} / \mathrm{ml}$, respectively, which the binding ability between ricin and anti-ricin pVHHS1 and 5S1R is in accordance with ELISA.

Using BIE for antibody evaluation, there are some advantages as follows. The first is non-touch and label-free. Non-touch ensures the detection without disturbance to samples, while label-free guarantees the operation with less labor consumption and less error introduced by labeling process. The second is demonstrated in the form of image format so that the inhomogeneity or unexpected contamination can be easily eliminated in time. Furthermore, it can realize high throughput protein analysis for multiple detection of numerous samples simultaneously. Its sensitivity and reproducibility can be improved by some optimization in experimental conditions including the surface modification, ligand immobilization, unspecific blocking, interaction condition control, etc., which basically meet the demand for various biomedical applications. In addition, BIE is a fast test approach about $1 \mathrm{~h}$ to detection ricin, while it spends at least $3 \mathrm{~h}$ with ELISA. This work presents BIE as a potential antibody screening platform.

\section{Acknowledgement}

The Chinese Academy of Sciences (KJCX2-YW-M03 and KJCX2YW-M04); the National Basic Research Program of China (2009CB320300); National Natural Science Foundation of China (20805053) and the National High Technology Research and Development Program (863) of China (2008AA02Z419) are acknowledged for their financial support.

\section{References}

[1] G. Kohler, C. Milstein, Nature 256 (1975) 495.

[2] C.L. Reading, J. Immunol. Meth. 53 (1982) 261.

[3] J. McCafferty, A.D. Griffiths, G. Winter, D.J. Chiswell, Nature 348 (1990) 552.

[4] L.J. Holt, C. Enever, R.M.T. de Wildt, I.M. Tomlinson, Curr. Opin. Biotechnol. 11 (2000) 445.

[5] F. Breitling, S. Dubel, T. Seehaus, I. Klewinghaus, M. Little, Gene 104 (1991) 147.

[6] K. Bussow, D. Cahill, W. Nietfeld, D. Bancroft, E. Scherzinger, H. Lehrach, G. Walter, Nucleic Acids Res. 26 (1998) 5007.

[7] R.M.T. de Wildt, C.R. Mundy, B.D. Gorick, I.M. Tomlinson, Nat. Biotechnol. 18 (2000) 989.

[8] J. Seideman, D. Peritt, J. Immunol. Meth. 267 (2002) 165.

[9] Y. Zhu, S.A. Jortani, C.Q. Simmons, R. Valdes, Clin. Chem. 50 (2004) A33.

[10] D. Heathcote, T. Carroll, J.J. Wang, R. Flower, I. Rodionov, A. Tuzikov, N. Bovin, S. Henry, Transfusion 50 (2010) 635

[11] G. Jin, P. Tengvall, I. Lundstrom, H. Arwin, Anal. Biochem. 232 (1995) 69.

[12] G. Jin, R. Jansson, H. Arwin, Rev. Sci. Instrum. 67 (1996) 2930.

[13] H.G. Zhang, C. Qi, Z.H. Wang, G. Jin, R.J. Xiu, Clin. Chem. 51 (2005) 1038.

[14] C. Qi, W. Zhu, Y. Niu, H.G. Zhang, G.Y. Zhu, Y.H. Meng, S. Chen, G. Jin, J. Viral Hepat. 16 (2009) 822.

[15] C. Qi, Y. Lin, J. Feng, Z.H. Wang, C.F. Zhu, Y.H. Meng, X.Y. Yan, L.J. Wan, G. Jin, Virus Res. 140 (2009) 79.

[16] C. Qi, X.S. Tian, S. Chen, J.H. Yan, Z. Cao, K.G. Tian, G.F. Gao, G. Jin, Biosens. Bioelectron. 25 (2010) 1530.

[17] G. Jin, Y.H. Meng, L. Liu, Y. Niu, S. Chen, Q. Cai, T.J. Jiang, 5th International Conference on Spectroscopic Ellipsometry, Albany, NY USA, 2010,, (TSF-D-10-00940).

[18] G.A. Balint, Toxicology 2 (1974) 77.

[19] S. Olsnes, Toxicon 44 (2004) 361.

[20] F. Musshoff, B. Madea, Drug Test. Anal. 1 (2009) 184.

[21] H.F. Shyu, D.J. Chiao, H.W. Liu, S.S. Tang, Hybrid. Hybridomics 21 (2002) 69

[22] J.W. Guo, B.F. Shen, J.N. Feng, Y.X. Sun, M. Yu, M.R. Hu, Hybridoma 24 (2005) 263.

[23] J.W. Guo, B.F. Shen, J.N. Feng, Y.X. Sun, M. Yu, M.R. Hu, Hybridoma 25 (2006) 225.

[24] G. Jin, Z.H. Wang, Int. J. Nonlinear Sci. Numer. Simul. 3 (2002) 191.

[25] Z.H. Wang, G. Jin, Anal. Chem. 75 (2003) 6119.

[26] G. Jin, Phys. Status Solidi A 205 (2008) 810.

[27] Z.H. Wang, Y.H. Meng, P.Q. Ying, C. Qi, G. Jin, Electrophoresis 27 (2006) 4078.

[28] Y.Y. Chen, Y.H. Meng, G. Jin, Appl. Opt. 46 (2007) 8475.

[29] Z.H. Wang, G. Jin, J. Biochem. Biophys. Meth. 57 (2003) 203.

[30] Z.H. Wang, G. Jin, J. Immunol. Meth. 285 (2004) 237.

[31] Z.H. Wang, G. Jin, Colloids Surf. B 34 (2004) 173.

[32] D. MacDougall, Anal. Chem. 52 (1980) 2242.

[33] G.L. Long, J.D. Winefordner, Anal. Chem. 55 (1983) A712. 